Véselka Nénkova ${ }^{1}$

UDK: 811.134.2'373.7

Universidad de Plovdiv

811.163.2'373.7

"Paisiy Hilendarski"

https://doi.org/10.18485/imp.2017.ch.11

\title{
LA MODIFICACIÓN FRASEOLÓGICA EXTERNA
}

En los textos periodísticos y publicitarios, la utilización de las unidades fraseológicas es una clara muestra de la creatividad lingüística humana. Las expresiones fijas suelen adaptarse de diversas maneras al contexto lingüístico que las incluye. La manipulación fraseológica se presenta como un procedimiento muy efectivo en el lenguaje y es una herramienta que los escritores y periodistas a menudo utilizan para conseguir diversos efectos comunicativos. El objetivo del presente trabajo consiste en identificar -a través de ejemplos en español y búlgaro- los diferentes mecanismos de modificación creativa externa de las expresiones fraseológicas (UFs) en el lenguaje literario y periodístico.

Palabras clave: fraseología, modificación fraseológica, manipulación externa, desautomatización, literalización.

Las recreaciones fraseológicas, conocidas comúnmente como transformaciones, desautomatizaciones, deslexicalizaciones, modificaciones, manipulaciones, fraseologismos ocasionales, deconstrucciones, rupturas, etc., son producto de la creatividad lingüística de los hablantes, quienes de forma consciente modifican las UFs para dotarlas de un sentido novedoso y ameno. Estas UFs tienen una gran fuerza evocadora y bastante carga emotiva, de tal forma que mantienen viva la atención del receptor. En este trabajo utilizaremos indistintamente los términos modificación fraseológica, manipulación creativa y transformación como sinónimos de la desautomatización de las UFs. Partiendo de una amplia concepción de la fraseología, realizaremos un análisis del tipo de modificación fraseológica externa que se produce en un corpus de 21 ejemplos localizados en obras literarias y la prensa españolas y búlgaras.

La desautomatización es un uso estratégico para lograr mejor el objetivo discursivo propuesto. Como se señala en Díaz Orozco et al. (2009:

veselka@gmail.com 
6), el efecto más buscado con la desautomatización tiene que ver con la retórica de la distracción, es decir, se propone reavivar la atención del receptor, distrayéndolo y refrescando a la vez la imagen subyacente de las UFs al deformar la expresión original. Las UFs desautomatizadas buscan llamar la atención del lector hacia la forma y el significado de la unidad originaria, haciendo el texto más interesante y lúdico. La función de las UFs modificadas puede ser humorística, irónica, sarcástica, apelativa, afectiva, expresiva, lúdica, etc. Todo ello explica el abundante número de expresiones modificadas en los textos periodísticos y literarios.

En la teoría fraseológica las modificaciones creativas se suelen dividir en dos grandes grupos: 1) modificaciones internas y 2) modificaciones externas. Las modificaciones internas son aquellas que se efectúan directamente sobre la estructura formal de las UFs y que pueden afectar al inventario de componentes o a las relaciones que se establecen entre ellos. Teniendo en cuenta los cambios internos, que intencionalmente se producen en la estructura de la UF, podemos distinguir entre modificaciones por sustitución léxica, por adición de lexemas, por supresión de elementos, por alusión, por modificación gramatical o sintáctica y también por modificaciones mixtas (Nénkova 2016). Las modificaciones externas, por su parte, juegan con el significado traslaticio o literal de una UF (Corpas Pastor 1996: 235-240). En las desautomatizaciones externas, por tanto, se juega, bien con la doble lectura de la UF (significado traslaticio y significado literal), bien con la lectura literal de alguno o algunos de los componentes de la UF, o bien con la adición de un comentario basado en la UF original.

La manipulación fraseológica puede basarse en una lectura ambigua, es decir, una vez identificada con su significado idiomático, la UF recibe otra interpretación al aplicarse a una situación en la que es posible que tenga un sentido distinto del fraseológico gracias al contexto en el que se pronuncia. Se trata del efecto de doble actualización ${ }^{2}$ que se da cuando, por las peculiaridades del contexto, se enfocan simultáneamente, tanto el significado figurado como la imagen de la UF (Dobrovol'skij 2009: 55).

En el juego fraseológico entre el significado literal y el significado idiomático no se producen modificaciones en el plano de la expresión,

2 término utilizado por Boldyreva (1967), cf. Dobrovol'skij (2009: 42) 
sino en el plano del contenido que actúa como soporte del juego verbal. De acuerdo con González Aguiar (2004: 89), el significado fijado (el fraseológico) actúa, pero de manera coocurrente con el significado literal. Veamos los siguientes ejemplos:

(1) Con la iglesia habían topado, y discutir más resultaba, amén de inútil, peligroso. (Arturo y Carlota Pérez-Reverte, El capitán Alatriste, 2002: 62)

En el caso que analizamos, Arturo y Carlota Pérez-Reverte juegan con el sentido fraseológico y el literal de la expresión con la iglesia hemos topado; la lectura fraseológica -que apunta a lo inconveniente de que en los asuntos propios se mezcle la iglesia o cualquier autoridad que suponga un obstáculo insuperable para lograr fines y propósitos- permanece latente, pero además entra en el juego creativo la lectura literal, pues los personajes no solo se hallan ante un obstáculo insuperable, sino que también realmente son perseguidos por la Inquisición. El cambio de persona y de tiempo en dicho ejemplo está impuesto por el contexto.

Un caso similar, de doble efecto interpretativo relacionado con el plano compositivo, lo hallamos con referencia a la UF pesar como un muerto 'pesar mucho'. El juego alusivo de los dos planos (el figurativo y el literal) hace referencia a que el hombre, al que el protagonista está arrastrando, en realidad, está muerto.

(2) - iCojones, pesa como un muerto! - se dijo con doble intención. (Pérez Gellida, Memento mori, 2013: 75)

Corpas Pastor (1996: 235) habla de la prominencia del significado compositivo en aquellos casos en que se activa el sentido literal y no el idiomático convencional de las UFs. Se trata, en general, de UFs en las que se identifica sin mucho esfuerzo la relación entre el significado literal y el idiomático. Zholobova (2015) utiliza el término literalización y explica que, a diferencia de la doble actualización, cuando interactúan el significado global y el significado literal, en el caso de la literalización, se aprecia la prominencia del significado literal de la UF y el fraseologismo debe interpretarse literalmente. El propio contexto, mediante los actualizadores, reactiva el significado literal de la UF, como en los siguientes ejemplos: 
(3) Ти си писал на държавата писма, обръщал си се към различни институции, на практика е станало като в онзи лаф да получиш оm умрял писмо. (Нека говорят, БТВ, 31.03.2013)

En un programa de la televisión búlgara BTV la periodista comenta el curioso caso del señor Alukov, el que escribió a varias instituciones búlgaras para que le resolvieran su problema. La historia es la siguiente: un amigo del señor Alukov fue ingresado en un hospital en el que se le efectuó una operación quirúrgica de la que el paciente no salió con vida. Sin embargo, como el paciente, previamente a la intervención, había acudido al hospital con la fotocopia del pasaporte del señor Alukov, debido a que éste había cotizado y tenía seguro médico y aquél no, las autoridades pusieron en el acta de defunción el nombre y los datos del señor Alukov. Para resolver el error, el "difunto" Alukov escribe cartas a las instituciones explicando el porqué de la confusión. La periodista hace un ingenioso comentario utilizando la UF да получиш от умрял писмо (tr. lit. recibir carta de un muerto) 'esperar algo en vano'. La UF en este caso concreto se interpreta con sus dos significados, el traslaticio y el literal, con prominencia del sentido literal, pues las instituciones búlgaras reciben cartas del señor Alukov, que -según el acta de defunción- está muerto.

Una interesante prueba de literalización la encontramos en el libro del historiador búlgaro Andrey Pantev:

(4) Ако библейският императив „око за око, зъб за зъб“ беше напълно осъществяван, досега човечеството щеше да бъде не само беззъбо, но и сляпо! (Пантев, Исторически паралели, 2011: 187) (tr. lit. Si el principio bíblico "ojo por ojo, diente por diente" se hubiera aplicado a rajatabla, hasta el momento presente la humanidad se habría quedado no solo desdentada, sino también ciega).

En este caso, cualquier comentario del ejemplo sería innecesario, ya que la traducción misma basta para demostrar la intención discursiva del profesor Pantev y su peculiar manera de cuestionar el significado de "las verdades absolutas". De nuevo se alude a la motivación de la locución y al propio proceso metafórico cognitivo que está en el origen de la formación de la frase. El lector está obligado a pensar, no en el significado 
traslaticio de la cita bíblica ojo por ojo y diente por diente que alude a la 'venganza justiciera', sino en el grupo verbal homónimo de la frase y su forma interior, es decir, sacar dientes y sacar ojos.

Un curioso ejemplo de literalización no intencionada lo observamos en la entrevista hecha el 15 de noviembre de 2014 en la cadena de televisión búlgara BTV. La entrevistada menciona que estudia chino y el periodista la sorprende con una conversación vía Skype con su profesora, que es china. La invitada exclama:

(5) Значи ти имаш номера на китайката! (БТВ, 120 минути, 15.11.2014)

La literalización aquí obviamente no es buscada, ya que la entrevistada no se refiere al significado idiomático de la UF búlgara номеръm на китайката (tr. lit. el número de la china) y menos aún a su significado 'conseguir algo mediante un truco que los otros no consiguen descifrar', sino que pronuncia esta frase porque se sorprende de que el presentador haya encontrado el número de la profesora china para acordar la conversación por Skype. Después de pronunciar la frase, el periodista y la entrevistada se echan a reír, puesto que en la mente de los dos inevitablemente ha surgido la asociación con la respectiva UF номерът на китайката.

Por la dificultad que supone la literalización de las UFs, los escritores y periodistas raras veces echan mano de ella; sin embargo, el desplazamiento literal, mediante la adición de un comentario basado en la UF original, es un recurso muy aprovechado. En el desplazamiento literal, a diferencia de la técnica de adición de elementos -que es una de las técnicas de modificación formal-, los componentes complementarios no afectan a la estructura de la UF original. La actualización que se realiza del significado de la UF se basa en la lectura literal de alguno de los elementos de la expresión a través de la repetición de éste en un comentario adicional. Así, una vez identificada con su significado idiomático, la UF recibe otra interpretación al aplicarse a una situación en la que es posible que tenga un sentido distinto del fraseológico gracias al contexto en el que se pronuncia. En el siguiente ejemplo, lo curioso y lo ingenioso del enun- 
ciado se basa en una lectura ambigua gracias a la relación que se establece entre el significado idiomático y el literal de la fórmula rutinaria la leche. En el fragmento se observa un desplazamiento hacia el significado literal debido a la adición de un comentario que obliga al lector a percibir la UF la leche en su sentido literal sin eliminar el significado fraseológico de la misma:

(6) Si huele el pescado entra en coma, los huevos le bloquean la glotis, la carne de ternera le desprende las uñas, o yo qué sé. La leche. También la leche le sienta como una patada en el hígado. (Pérez-Reverte, No me cogeréis vivo, 2006: 413)

La expresión vulgar la leche, que expresa enfado, protesta o sorpresa, está literalizada en este fragmento mediante el comentario adicional. El lector primero recoge el significado original de la UF y, acto seguido, reconoce la intención del periodista de jugar con el sentido recto de la expresión. Por lo tanto, en el ejemplo citado se hace referencia a los dos planos de la combinación, el plano idiomático y el plano literal. Los dos significados aparecen en una especie de un ameno juego lingüístico, gracias al cual se consiguen interesantes efectos discursivos que provocan la risa del lector.

La inmensa mayoría de UFs idiomáticas y semiidiomáticas constan de imágenes. Tienen, pues, las UFs icónicas o figuradas un sentido literal (la imagen) y un sentido metafórico (idiomático o semiidiomático) (Zuluaga 2001: 72). A través del desplazamiento del sentido idiomático hacia el literal alguno o algunos de los elementos del modismo recobran su significado literal y son aprovechados por los escritores y periodistas en busca de varios efectos lúdicos, como tenemos la ocasión de comprobar en los ejemplos que siguen a continuación:

(7) -No me tome el pelo -se llevó un índice a la sien-. Lo tengo gris, como el suyo. (Pérez-Reverte, La piel del tambor, 1998: 275).

(8) Su padre era un hombre de palabra, sí; pero, ay, también de muchas palabras [...]. (Jiménez, El vendedor de cerezas, 2013: 83) 
Los dos elementos pelo (en el ej. 7) y palabra (en el ej. 8) forman parte respectivamente de las locuciones tomar el pelo 'burlarse de alguien' y ser un hombre de palabra 'el que cumple con lo prometido'; sin embargo, en los comentarios añadidos pelo y palabra han recobrado su sentido literal.

(9) El que da primero da dos veces; pero lo que el refrán no especifica era que después de esas dos veces uno podía recibir doscientas. (PérezReverte, La carta esférica, 2000: 320)

En este fragmento, la oración complementaria, añadida por el autor, sirve para que el lector, después de la interpretación traslaticia, haga una lectura literal del refrán El que da primero da dos veces: el personaje fue el primero en atacar, pero acto seguido, recibió una enorme paliza que le hizo cuestionar la verdad absoluta del refrán que señala 'la ventaja que tiene uno al adelantarse a los demás o anticiparse a los acontecimientos por ser el primero en algo'.

Proponemos un ejemplo más de desplazamiento literal, esta vez en relación con el plano compositivo de la UF como si le fuera la vida en ello. La secuencia literal que sigue a la UF en cuestión invita a la lectura literal que hace referencia a la difícil situación en que se encuentra el personaje.

(10) Aún no había prendido un fósforo el Gitano Mairena cuando Peregil ya estaba corriendo a toda mecha a lo largo del muelle, de vuelta hacia el puente de Triana, como si le fuera la vida en ello. Que era exactamente lo que le iba. (Pérez-Reverte, La piel del tambor, 1998: 522)

En el siguiente fragmento, primero se cita la locución en su versión y significado original en todas partes cuecen habas 'hay problemas o disgustos en todas partes y circunstancias', luego, mediante la repetición de alguna de las palabras que forman la UF, aparecen alusiones al significado literal del componente en cuestión.

(11) Consuela comprobar que en todas partes cuecen habas, y que otros, a veces, incluso las cuecen más gordas. [...] al final las habas gordas de los demás también acabamos, indefectiblemente, cociéndolas nosotros. (Pérez-Reverte, XL Semanal, 16/6/2014) 
(12) - ¿Nos conocíamos ya? - Ahora sí que estaba perdida. Me ofreció un cigarrillo en una pitillera de oro. Me así a él como a un clavo ardiendo. Pero no ardía aún: me alargó fuego con un mechero naturalmente de oro. (Gala, Los papeles de agua, 2008: 365)

Aquí de nuevo se produce un desplazamiento literal; el cigarrillo se debe concebir como el clavo al que se agarra la protagonista en la conversación. El verbo arder en la oración adicional (Pero no ardía aún), conjugado en imperfecto de indicativo, impone que se haga una lectura literal del verbo. La doble lectura del componente verbal de la expresión agarrarse a un clavo ardiendo, 'valerse de cualquier recurso o medio, por difícil o arriesgado que sea, para salvarse de un peligro, evitar un mal que amenaza o conseguir alguna otra cosa', obliga al lector a hacer una interpretación contextual de la UF.

Hemos encontrado también un caso de desplazamiento del significado fraseológico hacia el significado simbólico de una de las palabras constituyentes de la UF ponérsele a uno la carne de gallina:

(13) Simplemente mirar las fotos en las que voy creciendo me pone la carne de gallina. A cada uno se le pone carne de lo que es. (Gala, Los papeles de agua, 2008: 61)

En este caso, Antonio Gala aprovecha la palabra gallina de la expresión fraseológica ponérsele a uno la carne de gallina 'erizar(le) la piel de miedo, impresión o repulsión' aprovechando el significado simbólico que posee la gallina en la cultura española, el de 'persona cobarde', para subrayar una vez más el débil carácter y la muy poca autoestima que posee la protagonista de la novela.

La estrategia de desplazamiento literal es muy aprovechada por Arturo Pérez-Reverte en los diálogos de sus novelas. Veamos los siguientes ejemplos:

(14) - [...]. Parecían incluso indignados, como si mismamente fuéramos a joder la marrana. No sé si me explico.

- Se explica, Murat. Con cierta dificultad, como de costumbre. Pero se explica. Prosiga. (Pérez-Reverte, La sombra del águila, 2007: 102) 
El significado de la fórmula no sé si me explico, que 'se usa expletivamente para pedir comprensión al interlocutor sobre el verdadero sentido de lo que se dice', ha sido literalizado por el interlocutor mediante los elementos propios del discurso libre: Se explica, Murat. Con cierta dificultad, como de costumbre. Pero se explica. Así, la expresión consigue ridiculizar al personaje y tiñe de humorismo la situación.

En la misma línea se sitúan los siguientes ejemplos de diálogos en que, mediante el comentario que añade el segundo interlocutor, se procede a la lectura literal de las UFs completas o solo de alguno de sus elementos:

(15) -Los caminos de Dios son inescrutables -dijo, por decir algo.

-Pues este camino tiene muy mala sombra. (Pérez-Reverte, La piel del tambor, 1998: 299)

(16) -Ya la oyes. Es mi ángel de la guarda.

- ¿De veras? Pues podría cuidarte mejor. (Pérez-Reverte, El club Dumas, 1998: 394)

(17) -Hay gato encerrado.

-Me encantan los gatos. Sobre todo, si sus dueñas son rubias y guapas. (Pérez-Reverte, El club Dumas, 1998: 148)

(18) -Es usted un hijo de mala madre, Larrea.

-Contando con que la mía me abandonó antes de cumplir los cuatro años, no veo manera de contradecir tal afirmación - replicó acercándose al pequeño buró que ocupaba una esquina de la alcoba. (Dueñas, La Templanza, 2015: 488)

En todos los ejemplos arriba citados los fraseologismos no se ven alterados en su forma, pero con la alusión o la repetición de alguna de las palabras constitutivas de las UFs, se produce un cambio externo que aprovecha la imagen de la expresión fraseológica para adaptarla al contexto.

Muy interesante resulta el siguiente diálogo en que al adjetivo vivo, utilizado por el primer interlocutor, el segundo interlocutor añade el gerundio coleando. Reuniendo así los dos elementos de la UF vivo y coleando, el protagonista evoca el sentido traslaticio de la expresión: 'persona que tiene toda su vitalidad'. 
(19) -Un buen escritor para empezar a considerar un posible tema de su tesis. Y, además, un amigo.

Le lanzó entonces un libro por encima de la gran mesa de trabajo.

-¿Vivo? -preguntó Daniel atrapándolo hábilmente con la mano izquierda.

$-Y$ coleando. Enseña literatura moderna en Albuquerque, Nuevo México. $Y$ sigue escribiendo. Acabo de estar con él en el congreso de narrativa en Amherst. (Dueñas, Misión olvido, 2012: 133)

La desautomatización externa se puede presentar también mediante el encadenamiento de dos o más fraseologismos que no sufren alternancias formales en sus estructuras. Estas UFs entran en un juego en que sus significados interactúan y dan como resultado un ingenioso juego fraseológico.

(20) -Da igual. Ya estamos otros para poner la letra pequeña.

-La que con sangre entra. (Pérez-Reverte, Hombres buenos, 2015: 515)

En este ejemplo, el sustantivo letra, que es el núcleo de la UF letra pequeña, 'conjunto de condiciones o cláusulas secundarias en un acuerdo o contrato', mencionada por el primer interlocutor, da pie al otro para echar mano de la UF la letra con sangre entra, que expresa que 'para conseguir éxito en los estudios hay que esforzarse mucho', cuyo núcleo es el mismo sustantivo (letra), lo que facilita la omisión de este en la UF citada: la que con sangre entra.

(21) Вдигаме ръце, но и ги потриваме. (Калин Терзийски, БНТ 1, Денят започва 10.02.2015)

La fusión entre las dos UF búlgaras вдигам ръце 'resignarse, dejarlo o abandonarlo' (esp. levantar (la) mano de algo) у потривам ръце 'manifestar gran satisfacción por algo' (esp. frotarse las manos) explican de una forma muy clara y exhaustiva la desesperación del escritor y psiquiatra Kalin Terziyski respecto a la imposibilidad de que en Bulgaria se resuelva el problema de las personas con trastornos psíquicos. Ambas UFs comparten en sus formas canónicas un mismo constituyente (manos), lo que facilita la unión de las dos unidades.

En conclusión, el análisis de los ejemplos sacados de varios textos literarios y periodísticos nos ha permitido el reconocimiento de diferentes 
posibilidades de manipulación externa de las expresiones fijas. Las técnicas de modificaciones creativas no producirían los efectos deseados si los usuarios no poseyeran un conocimiento previo de las UFs. Puesto que las modificaciones externas no afectan a la estructura interna y/o formal de la combinación, a menudo son imperceptibles a simple vista si no se presentan junto a su contexto. Gracias al estudio realizado, podemos afirmar que los escritores y periodistas aprovechan de manera muy original y divertida las características particulares de las UFs para conseguir diversos efectos comunicativos y hacer más amena la comunicación con sus lectores, espectadores y oyentes.

\section{BIBLIOGRAFÍA}

Corpas Pastor, Gloria. Manual de fraseología española. Madrid: Gredos, 1996. Impreso.

Díaz Orozco, Viviana, et al. "Funciones de los fraseologismos en la novelística de García Márquez: el caso de la desautomatización". Revista Virtual Universidad Católica del Norte, № 26 (2009). Web. 06.082014.

Dobrovol'skij, Dmitrij. "La variación léxico-sintáctica en la fraseología: la introducción del atributo en la estructura de la locución idiomática”. Language Design, № 11 (2009): 29-65. Web. 01.10.2015.

González Aguiar, María Isabel. "La utilización de las unidades fraseológicas en las viñetas de los periódicos españoles". Revista de Filología (2004): 79-94. Impreso.

Nénkova, Véselka. La manipulación creativa de las unidades fraseológicas en el lenguaje literario, periodístico y publicitario. Plovdiv: Editorial Universitaria "Paisiy Hilendarski", 2016. Impreso.

Zholobova, Anna. "Manipulación creativa de los bibleísmos fraseológicos en español". Tonos Digital, № 28 (2015). Murcia: Universidad de Murcia. Web. 03.04.2015.

Zuluaga, Alberto. "Análisis y traducción de unidades fraseológicas desautomatizadas". PhiN, 16 (2001). Web. 05.09.2015.

\section{FUENTES LITERARIAS}

Dueñas, María. Misión olvido. Madrid: Planeta, 1012. Impreso.

Dueñas, María. La Templanza. Madrid: Planeta, 2015. Impreso. 
Gala, Antonio. Los papeles de agua. Barcelona: Planeta, 2008. Impreso. Jiménez, Santos. El vendedor de cerezas. Toledo: CELYA, 2013. Impreso. Пантев, Андрей. Исторически паралели. София: Анубис, 2011. Impreso. Pérez Gellida, César. Memento mori. Madrid: Conspicua, 2013. Impreso. Pérez-Reverte, Arturo. El club Dumas. Madrid: Alfaguara, 1998. Impreso. Pérez-Reverte, Arturo. La piel del tambor. Madrid: Alfaguara, 1998. Impreso. Pérez-Reverte, Arturo. La carta esférica. Madrid: Alfaguara, 2000. Impreso. Pérez-Reverte, Arturo y Carlota Pérez-Reverte. El capitán Alatriste. Madrid: Alfaguara, 2002. Impreso.

Pérez-Reverte, Arturo. No me cogeréis vivo (2001-2005). Alfaguara: Madrid, 2006. Impreso.

Pérez-Reverte, Arturo. La sombra del águila. Madrid: Santillana, 2007. Impreso. Pérez-Reverte, Arturo. Hombres buenos. Madrid: Alfaguara, 2015. Impreso.

\title{
FUENTES ORALES
}

БHТ1

БTB

\section{Véselka Nénkova}

\section{EXTERNAL PHRASEOLOGICAL UNIT BREAKING}

\begin{abstract}
Summary
The use of phraseological units in newspaper articles is a clear example of intelligent linguistic creativity. Fixed expressions have the ability to adapt in various ways to the contexts in which they are included. Phraseological manipulation is presented as a very effective procedure in language and it is a tool that writers and journalists often use in order to achieve different communicative purposes. By means of different examples in Spanish and Bulgarian we are going to demonstrate the effectiveness and the potential of external phraseological unit breaking in literary and journalistic language.
\end{abstract}

Keywords: phraseology, phraseological units, creativity, phraseological modification, external phraseological unit breaking, desautomatization. 